\title{
The comfort of knitted fabric: interaction of sportswear and athlete's body
}

\author{
Ivana Salopek Čubrić ${ }^{1}$, Goran Čubrić ${ }^{1, *}$, Vesna Marija Potočić Matković ${ }^{1}$, Alenka Pavko \\ Čuden ${ }^{2}$ \\ 1 University of Zagreb, Faculty of Textile Technology, Zagreb, Croatia \\ 2 University of Ljubljana, Faculty of Natural Sciences and Engineering, Ljubljana, Slovenia \\ ${ }^{*}$ Corresponding author E-mail address: goran.cubric@ttf.unizg.hr
}

\section{INFO}

CDAPT, ISSN 2701-939X

Peer reviewed article

2021, Vol. 2, No. 1, pp. 70-79

DOI 10.25367/cdatp.2021.2.p70-79

Received: 28 April 2021

Accepted: 11 June 2021

Available online: 08 July 2021

\section{Keywords}

Knitted fabric,

Comfort,

Properties,

Polyester,

Sport,

Temperature,

Thermography,

Body

\begin{abstract}
The properties of the material used for the production of sportswear directly affect the heat exchange and sweat transfer that occurs at the interface between the skin and the environment. Thermography is a valuable method that provides insight into the patterns of temperature distribution on the surface of human skin that change during sports training or intense exercise. Such patterns can be further used to improve the design of sportswear. The experiment presented in this paper focuses on studying the changes in body temperature of the participating subjects during two typical types of training in football (condition training and tactical training). The duration of each training session was 60 minutes and measurements were taken after each of the total 10 training sessions. A thermal camera was used to measure the upper body temperatures of the players and professional software was used for further processing of the thermal images. In the analysis of the thermal data, the average temperatures for 9 anterior and 9 posterior zones of the upper body were obtained. The results related to the changes in average temperature for each observed anterior and posterior zone and two types of football training are presented and discussed.
\end{abstract}

(C) 2021 The authors. Published by CDAPT. This is an open access article under the CC BY-NC-ND license https://creativecommons.org/licenses/ peer-review under responsibility of the scientific committee of the CDAPT.

(c) 2021 CDAPT. All rights reserved.

\section{Introduction}

Research related to football includes various topics such as sociological studies, physiological, psychological, technical and tactical elements of the sport, coaching, and the prevalence of injuries. 
Physiological thermoregulation, triggered by temperature signals from the body and skin during athletic activity, attracts research. During athletic activity, the core temperature of the body increases, a limited amount of energy is converted to mechanical energy, while the rest is converted to thermal energy. The body has the ability to lose heat through evaporation of moisture on the skin. Thermoregulation is related to the thermal comfort of clothing [1]. Therefore, there is a growing interest in the thermal properties and moisture management of fabrics for sportswear, as well as in the properties of the fibers and yarns from which they are made.

Thermography as a noninvasive and rapid measurement is widely used in sports science. The validity and reliability of this method for measuring skin temperature has been documented in a number of sports. Thermography for measuring thermoregulation of football players was used in the study by Dębiec-Bąk et al. [2]. The results of the study indicate better effectiveness of thermoregulatory processes in football players compared to students. In another study, a novel injury prevention program based on infrared thermography was established and its influence on injury incidence in professional soccer players was investigated [3]. The incidence of injuries was reduced by identifying players potentially at risk, and injury severity and days lost were also reduced.

The relationship between energy expenditure and skin temperature during swimming protocol (front crawl and backstroke) was investigated by Seixas et al. [4]. Both swimming techniques increased skin temperature, but with different thermal patterns. Thermography was used in cycling to investigate the effects of saddle height on thermoregulation [5]. The aim of this study was to investigate whether different cycling postures, caused by different knee flexion angles, could affect skin temperature. In another experiment, thermography was used to investigate the changes in body temperatures of participating divers due to different wetsuit thickness and thermal environment [6]. The thermography showed the great influence of the environmental temperature, wetsuit thickness and physiology of the divers on the changes of skin temperature during immersion over time. In a study of runners, thermography was compared with thermal contact sensors to define the methodology for further research [7]. The stationary sensor showed a higher skin temperature after running than infrared thermography. Another study on runners investigated the relationship between skin temperature changes and muscle fatigue [8]. Correlation analysis performed to quantify the relationship between performance and temperature change over time showed that there was a significant negative correlation between the increase in skin temperature and the decrease in performance of the exercising quadriceps. A systematic literature review on the use of thermal imaging for the diagnosis of musculoskeletal injuries was conducted and found that infrared thermal imaging is a good diagnostic tool for musculoskeletal injuries [9]. Interestingly, no significant relationship was found between measured skin temperature and subjective assessment of muscle soreness in junior athletes [10].

Technical developments in the field of sportswear, high performance textiles and knitted fabrics for sportswear are also attracting increasing research attention. Knitted fabrics are preferred for sportswear due to their water vapor permeability, air permeability, thermal conductivity and moisture management as well as better elasticity and stretchability as compared to woven fabrics. Thermography was used by Salopek et al. to develop suggestions for sportswear for futsal players based on thermal body mapping [11]. The results of the study showed the importance of adapting the construction and fit of the clothing to the type of training. Heat and moisture transfer and air permeability in single jersey knitted garments and their influence on comfort were studied by Gupta et al. [12]. Finer yarns and higher loop lengths of knitted fabrics were more permeable to air and water vapor, making them more suitable for humid conditions. Nemeckova et al. used the method to measure moisture transport on knitted fabrics using thermographic and micro-thermographic systems [13]. Three types of knitted fabrics with the same raw material composition and fineness but different construction were studied, of which the interlock structure was shown to give the best results in terms of liquid absorption and transfer. In another study, thermography was used to observe the influence of different yarn types on the total drying time of knitted fabrics, which directly affect human comfort [14]. The results showed significant differences in total drying time between fabrics and the influence of elastane yarn on total drying time. 
Synthetic fabrics are generally considered a better alternative for sportswear than natural fibers because they provide good heat and moisture management, allowing body temperature to be regulated. Polyester (PES) is the most commonly used fiber in sportswear because it is dimensionally stable, very durable, easy to care for, wrinkle resistant, and highly stain resistant. Hes and Ursache [15] investigated the cooling effect of knitted fabrics under simulated sweating conditions. They found that the highest cooling effect occurred with fabrics made of PES filaments with a grooved surface, which conduct moisture along the fabric. When polyamide or cotton fibers were present in the structure, the cooling effect was lower. The thermal resistance and air and water vapor permeability of various commercially available PES yarns were studied by Souza et al. [16]. The knitted fabrics with the highest thermal resistance values and the lowest heat absorption capacity and heat flow were those with higher air content in the fabric structure, which slowed down the heat transfer process. The air permeability of the fabrics seemed to depend on the fiber morphology. In terms of moisture management, Coolmax yarns achieved the best performance and Airclo and Seacell showed the best performance in terms of thermal regulation. The water vapor transport behavior of PES knitted fabrics with different thicknesses, densities, porosities and fiber cross-sectional properties was investigated by Prahsarn et al. using upright cup method, guarded sweating hot plate method and dynamic sweating hot plate apparatus [17]. The primary design criterion for a fabric for high water vapor transport performance is a structure that is both thin and open.

In this study, thermography was used to observe the changes in skin temperature of football players wearing PES knitted sportswear. A FLIR E6 thermal camera was used for the measurements [18].

\section{Methods and Materials}

The experiment presented in this manuscript focuses on studying the changes in body temperature during two typical football training sessions. A T-shirt (size L, in blue color, manufactured by Fotex company, Croatia) used as part of the official football clothing was selected for the study. The characteristics of the weft knitted fabric used for the production of T-shirts and the microscopic image are given in Table 1. The breaking force and breaking elongation of fabric were tested using the tensile tester Statimat M (Textechno Herbert Stein GmbH \& Co. KG, Mönchengladbach, Germany). The gauge length of the tensile tester was $(100 \pm 1) \mathrm{mm}$ and the dimensions of specimen $(50 \pm 0.5) \mathrm{mm} \times(200 \pm$ $0.5) \mathrm{mm}$. Specimen were cut in the direction of wales and courses.

Table 1. Characteristics of knitted fabric. Dh/Dv = density horizontal/vertical.

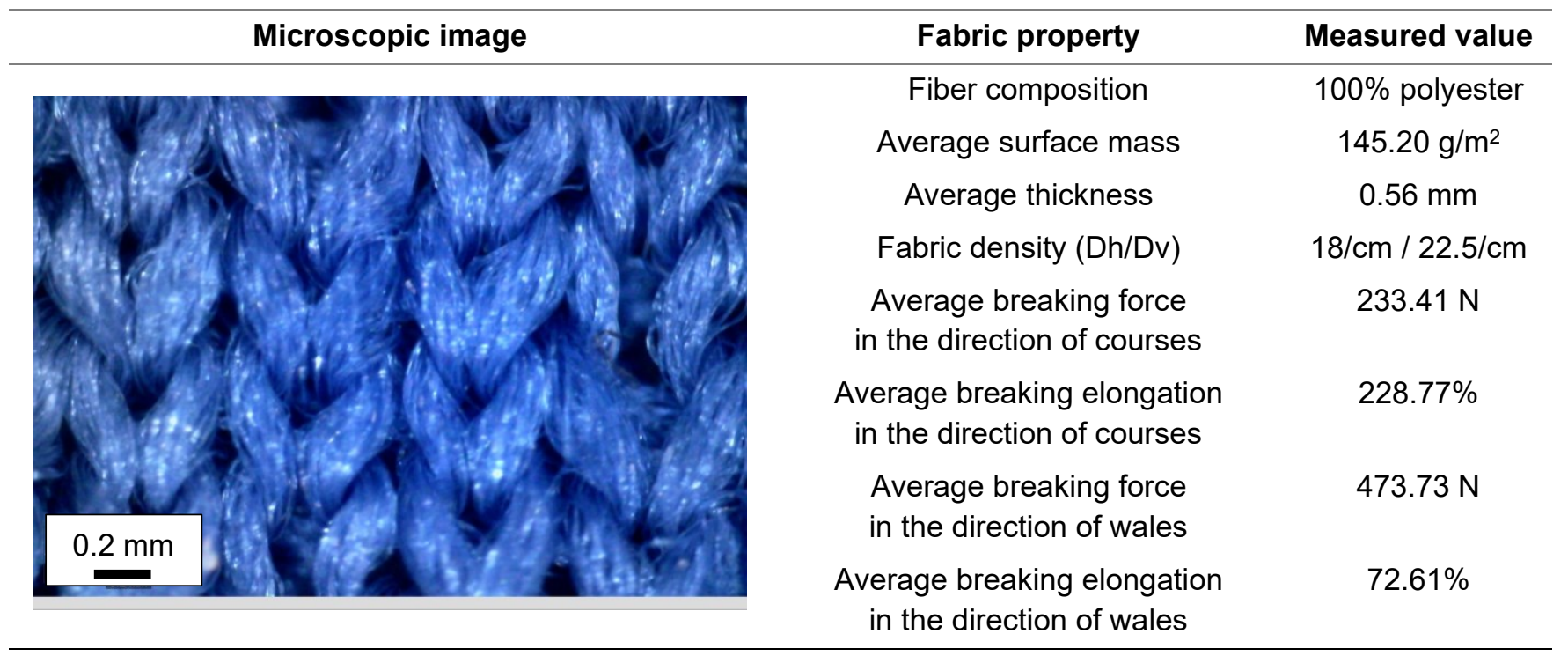

The participants were four male veteran footballers in good health who had no health disorders, such as cardiovascular or metabolic disorders, and were assessed as healthy by completing a general health questionnaire. All were non-smokers and not taking any medication. The participants were (42 \pm 3$)$ years 
old, had a body weight of $(82 \pm 5) \mathrm{kg}$ and a height of $(180 \pm 5) \mathrm{cm}$. The research with the participation of volunteers was approved by the Ethics Committee of the University of Zagreb, Faculty of Textile Technology. The volunteers were advised not to eat one hour before the training sessions and not to consume alcoholic beverages $24 \mathrm{~h}$ before. During the training sessions, the volunteers wore the predetermined T-shirt as well as shorts, socks, and sneakers. They wore the same outfit during the measurements (both before and after training). They were further advised to take the usual amount of water. Before and after the training sessions, temperature measurements were taken on the entire upper body of the player. The experiment focused on two types of typical football training: condition training (further referred to as Tr1) and tactical training (further referred to as Tr2). The duration of each training session was 60 minutes and measurements were taken after each of the total 10 training sessions. Training sessions were held at 1-2 day intervals. The main difference between these two types of training is that tactical training is performed with the ball, while condition training is performed without the ball. Both types of training start with warm-ups and end with stretching. Condition training includes running, push-ups, crunches, burpees, etc., while tactical training includes ball control and passing, turning and facing, cone weaving, etc. Between each series of exercises, the volunteer had breaks of 30 to 60 seconds to refresh himself.

The FLIR E6 thermal camera (Flir Systems Inc, USA) was used to measure the upper body temperatures of the players at a distance of $2 \mathrm{~m}$, always at the same location. The specifications of the camera used are: IR resolution $120 \times 90$ pixels; thermal sensitivity $<0.10{ }^{\circ} \mathrm{C}$, field of view $45^{\circ} \times 34^{\circ}$, temperature range $0{ }^{\circ} \mathrm{C}$ to $150^{\circ} \mathrm{C}$ (standard range is $-20^{\circ} \mathrm{C}$ to $+250{ }^{\circ} \mathrm{C}$ ), emissivity correction: variable from 0.1 to 1.0 (set to 0.98 in these measurements). The camera was held vertically and all measurements were performed by one person according to the suggestions given in ISO 18434-1:2008 [19]. The example of thermograms for the anterior and posterior body is shown in Figure 1 . The measurement was performed indoors with a controlled temperature of $(21 \pm 0.5){ }^{\circ} \mathrm{C}$ and relative humidity of $(50 \pm 5) \%$, without ventilation. Measurements were taken in the afternoon, during the spring season, just before the start of training and just after the end of training. The professional software FLIR Tools ${ }^{\circledR}$ (Flir Systems Inc, USA) was used for further processing of the thermal images.

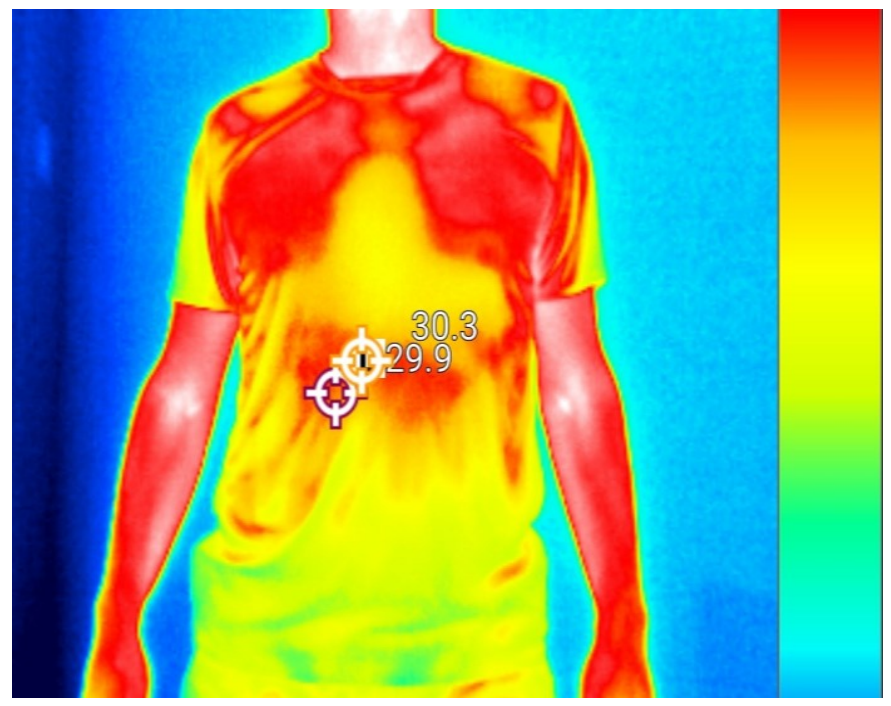

(a)

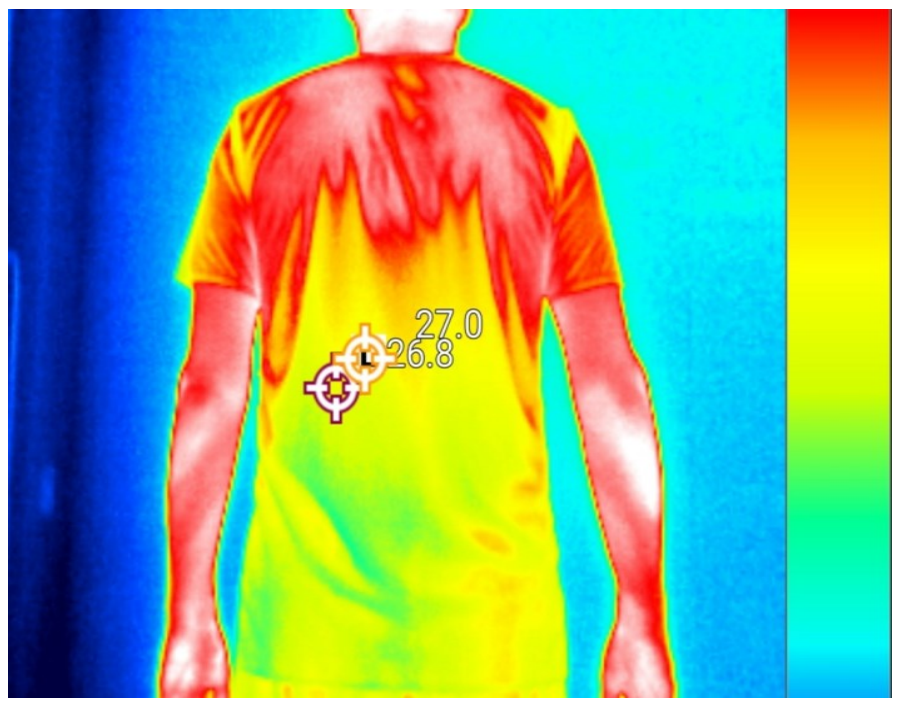

(b)

Fig. 1. Example of a thermal images taken before training for: (a) anterior part of the body; (b) posterior part of the body.

In the analysis of thermal data, average temperatures were defined for 9 anterior and 9 posterior zones of the upper body, as depicted in Table 2. The variation of measured temperatures between participating footballers was up to $5 \%$ for a single observed zone. 
Table 2. Observed body zones.

\begin{tabular}{llll}
\hline \multicolumn{2}{l}{ Anterior body zones } & \multicolumn{2}{l}{ Posterior body zones } \\
\hline Designation & Description & Designation & Description \\
\hline$z 1 a$ & Right upper arm & $z 1 p$ & Right upper arm \\
$z 2 a$ & Right chest & $z 2 p$ & Right upper back \\
$z 3 a$ & Mid chest & $z 3 p$ & Mid upper back \\
$z 4 a$ & Left chest & $z 4 p$ & Left upper back \\
$z 5 a$ & Left upper arm & $z 5 p$ & Left upper arm \\
$z 6 a$ & Right abdomen & $z 6 p$ & Right lower back \\
$z 7 a$ & Mid abdomen & $z 7 p$ & Mid lower back \\
$z 8 a$ & Left abdomen & $z 8 p$ & Left lower back \\
$z 9 a$ & Anterior pelvis & $z 9 p$ & Posterior pelvis \\
\hline
\end{tabular}

\section{Results and discussion}

The results in terms of differences in absolute temperature between the measured pre-training body temperatures and the post-training body temperatures are shown in Figures 2 and 3 . The results are presented for each observed anterior and posterior zone and two types of football training, i.e. condition training (Tr1) and tactical training (Tr2).

Figure 2a shows that after condition training the body temperature in the anterior upper arm and chest zones drops by up to $2 \mathrm{~K}$. The situation is quite different after tactical training, where the body temperature in the anterior chest area increases by up to $1 \mathrm{~K}$, while it decreases in the upper arms. There is also a difference in temperature change between the left and right upper arms.

As can be seen in Figure $2 b$, body temperature decreases in the anterior right and mid abdominal and pelvic zones after condition training, while it increases in the anterior left abdominal zone. The temperature decrease in the anterior right abdominal zone is more than $3 \mathrm{~K}$. The difference in temperature change between the left and right abdominal sides of the body is even greater than in the upper arms. After tactical training, body temperature decreases by up to $2 \mathrm{~K}$ in the anterior left and middle abdominal zones. Again, the difference in temperature change between the left and right abdominal sides of the body sides is clear.

Figures $3 a$ and $3 b$ show that after both condition and tactical training, body temperature decreases by 1.2-3.7 $\mathrm{K}$ in all posterior body zones. The decrease is most pronounced in the right chest and mid abdominal zones. The differences in temperature change between left and right side of the body are also significant.

From the comparison of Figures 2 and 3, the significant differences between the absolute temperatures in the anterior and posterior body zones can also be seen. 

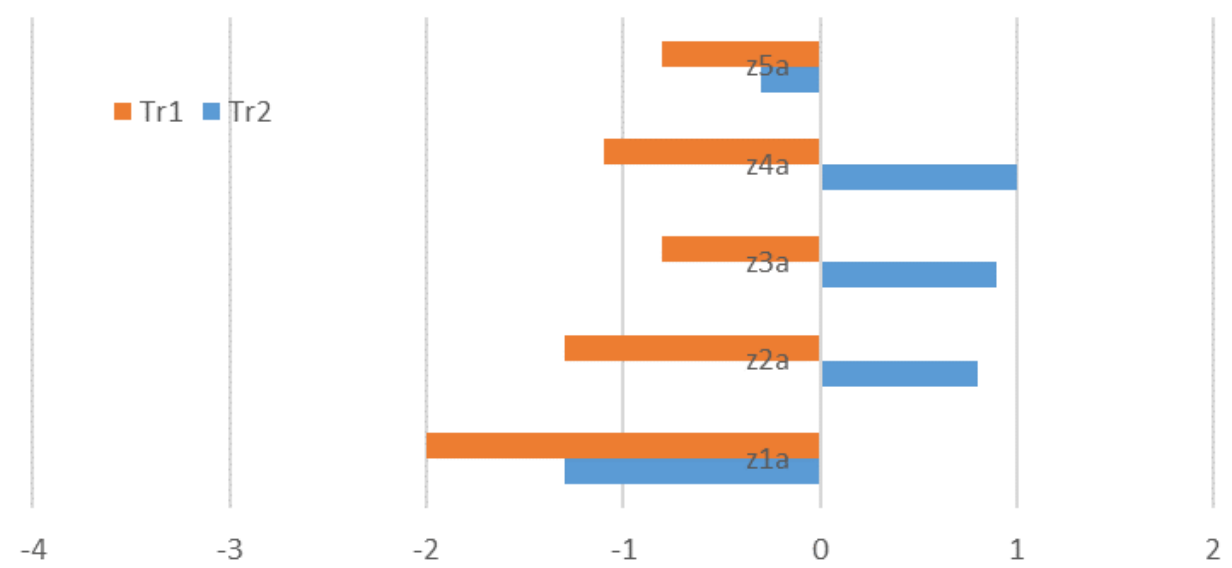

Absolute temperature difference (K)

(a)

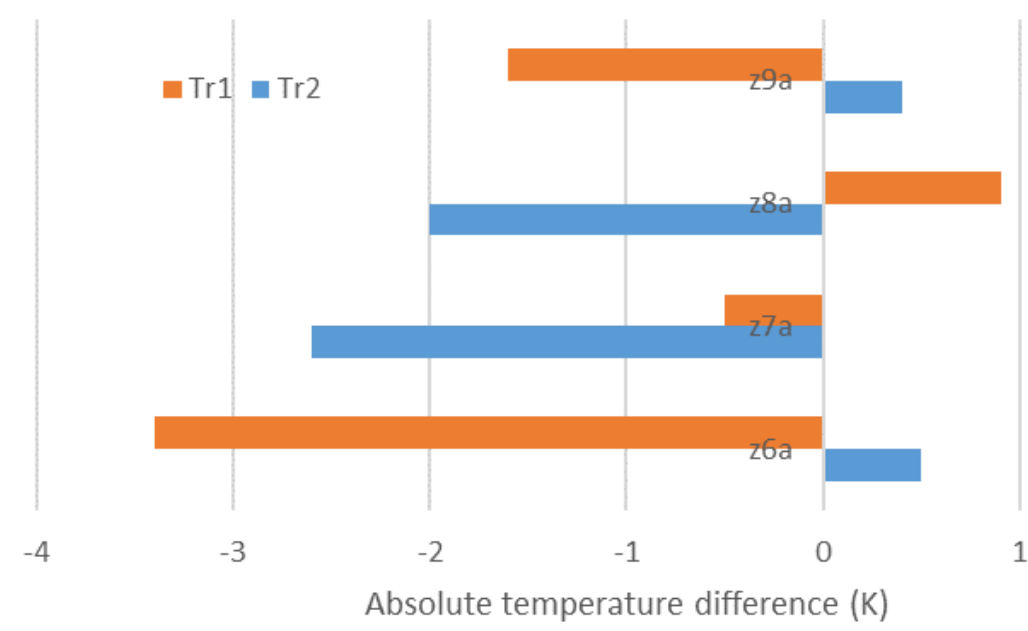

(b)

Fig. 2 Absolute temperature difference for anterior body zones (a) zones z1a-z5a; (b) zones z6a-z9a.

The decrease in skin temperature over the selected muscle zones of the upper body seems to be related to the cooling effect of sweat evaporation. Sweating is the main thermoregulatory response by which heat balance is maintained after a rise in body temperature during exercise-induced heat load. Evaporation of sweat from the skin surface has a cooling effect because evaporation is an endothermic process [20]. It is important to consider other factors that could influence differences in skin temperature between body regions [21]. Body movement causes air movement around the body and could increase heat consumption and lead to lower local skin temperatures. Thermal insulation of clothing and obstruction of sweating may also cause differences in different body zones. On the other hand, sweating may moisten the clothing locally and evaporation may cause the local body temperature decrease. Individual characteristics of the subject (genetic and/or anthropometric and/or training factors) may also influence the skin temperature change $[15,16]$. 


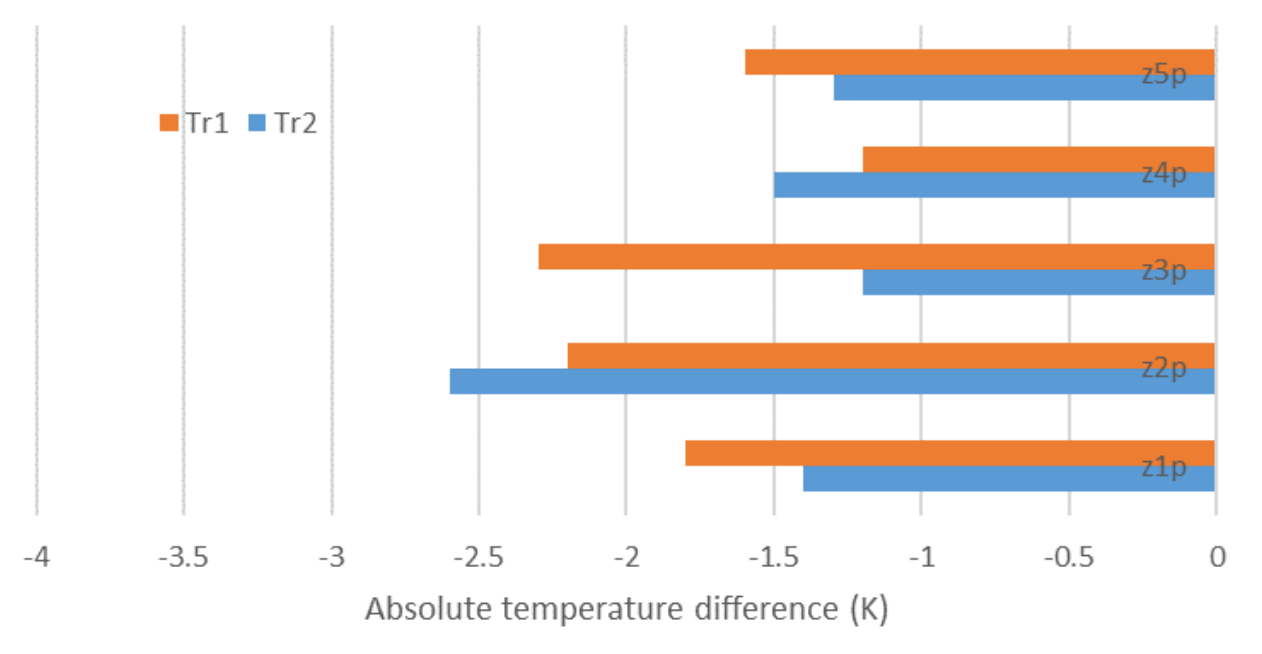

(a)

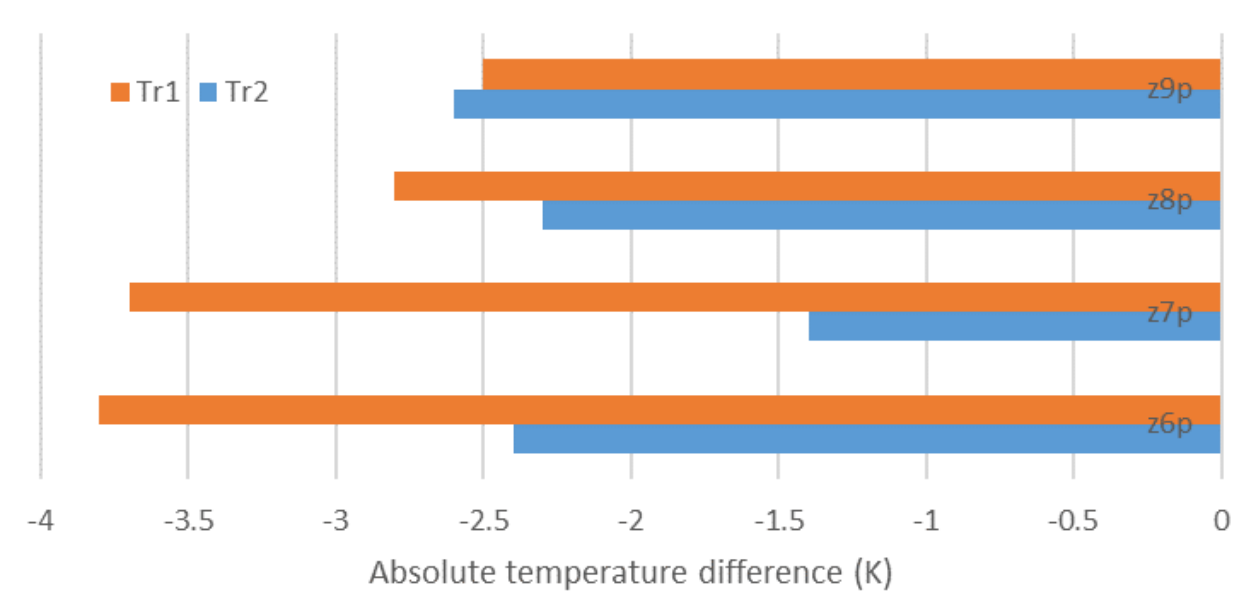

(b)

Fig. 3 Absolute temperature difference for posterior body zones (a) zones z1p-z5p; (b) zones z6p-z9p.

The type of training also affects the change in body temperature. During graded load exercise, where the load on the body progressively increases (and the blood demand of the working organs also increases), the mean skin temperature decreases throughout the exercise. A continuous vasoconstrictor response, resulting in a progressive decrease in blood flow with increasing exercise intensity, is thought to be the reason for the decrease in mean skin temperature. In the case of constant load exercise, skin temperature decreases at the beginning of work due to the initial vasoconstriction of the skin and then reaches a minimum value, followed by a small and gradual increase over time. It is argued that the initial decrease and subsequent small increase in skin temperature is the net result of competition between the vasoconstrictor response, which lasts as long as the exercise continues, and the vasodilator response, which is induced by increasing body temperature [22].

The results of the unpaired t-test are determined with $\alpha=0.05$. The test compared the values of measured body zone temperatures after the training activity for two types of training. The results are given in Table 3 . According to the $p$-value given, the differences are considered not statistically significant. As can be seen from the same table, a significant difference $(p<0.05)$ is defined only for the posterior pelvic zone. 
Table 3. Results of the t-test.

Anterior body zones

\begin{tabular}{lll}
\hline Designation & Description & -value \\
\hline z1a & Right upper arm & 0.6692 \\
z2a & Right chest & 0.8621 \\
z3a & Mid chest & 0.7385 \\
z4a & Left chest & 0.9492 \\
z5a & Left upper arm & 0.6534 \\
z6a & Right abdomen & 0.5547 \\
z7a & Mid abdomen & 0.4176 \\
z8a & Left abdomen & 0.8975 \\
z9a & Anterior Pelvis & 0.9340 \\
\hline Posterior body zones & & \\
\hline Designation & Description & -value \\
\hline z1p & Right upper arm & 0.5782 \\
z2p & Right upper back & 0.5400 \\
z3p & Mid upper back & 0.7693 \\
z4p & Left upper back & 0.3481 \\
z5p & Left upper arm & 0.9799 \\
z6p & Right lower back & 0.6776 \\
z7p & Mid lower back & 0.7389 \\
z8p & Left lower back & 0.7697 \\
z9p & Posterior pelvis & 0.0263 \\
\hline
\end{tabular}

\section{Conclusions}

The aim of this work was to compare the changes in temperatures of the anterior and posterior body zones of an athlete due to different types of training. The results showed that:

- after condition training, body temperature in the anterior upper arm and chest zones decreases by up to $2 \mathrm{~K}$, while after tactical training, it increases by up to $1 \mathrm{~K}$ in the anterior chest zone;

- after condition training, body temperature decreases in the anterior right, mid abdominal and pelvic zones, while after tactical training it decreases in the anterior left and middle abdominal zones;

- after both types of training, body temperature decreases by 1.2-3.7 K in all posterior body zones;

- for a number of zones, significant differences between left and right sides of the body are observed.

The results of the study are expected to be applied in the design and development of specific sportswear for high-level professional football players. More specifically, these results can be used to design T-shirts in which individual cut parts (in specific body zones) are made of materials with different properties, especially in terms of sweat transfer. 


\section{Acknowledgement}

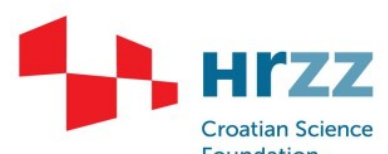

Foundation

This work has been fully supported by Croatian Science Foundation under the project IP-2020-02-5041 Textile Materials for Enhanced Comfort in Sports TEMPO.

\section{References}

[1] George Havenith. 1999. Heat balance when wearing protective clothing. Ann. Occup. Hyg. 43, 5, 289-296. DOI: https://doi.org/10.1016/S0003-4878(99)00051-4.

[2] Agnieszka Dębiec-Bąk, Łukasz Pawik and Anna Skrzek. 2016. Thermoregulation of football players after cryotherapy in thermography. J. Therm. Anal. Calorim. 126, 1, 1633-1644. DOI: https://doi.org/10.1007/s10973-016-5623-3.

[3] Pedro Gomez-Carmona, Ismael Fernández-Cuevas, Manuel Sillero-Quintana,Javier Arnaiz-Lastras, and Archit Navandar. 2020. Infrared Thermography Protocol on Reducing the Incidence of Soccer Injuries. Journal of Sport Rehabilitation 29, 8, 1222-1227. DOI: https://doi.org/10.1123/jsr.2019-0056.

[4] Adérito Seixas, Gonjo Tomohiro, Ricardo Vardasca, Joaquim Gabriel Mendes, Ricardo Fernandes and J. Vilas-Boas. 2014. A preliminary study on the relationship between energy expenditure and skin temperature in swimming. In Proceedings of the QIRT2014 - The 12th International Conference on Quantitative InfraRed Thermography, July 2014, Bordeaux. DOI: https://doi.org/10.21611/qirt.2014.097.

[5] Jose Ignacio Priego Quesada, Felipe P. Carpes, Rosario Salvador Palmer, Pedro Pérez-Soriano and Rosa M. Cibrián Ortiz de Anda. 2016. Effect of saddle height on skin temperature measured in different days of cycling. SpringerPlus 5, 205, 1-9. DOI: https://doi.org/10.1186/s40064-016-1843-z.

[6] Vesna Marija Potočić Matković and Ivana Salopek Čubrić. 2018. Performance of neoprene wetsuits in different underwater thermal environments. In Proceedings of 7th International Ergonomics Conference - Ergonomics 2018, June 13-16, 2018, Zadar, Croatia.

[7] Jose Ignacio Priego-Quesada, Alvaro S. Machado, Marina Gil-Calvo, Irene Jimenez-Perez, Rosa M. Cibrian Ortiz de Anda, Rosario Salvador Palmer and Pedro Perez-Soriano. 2020. A methodology to assess the effect of sweat on infrared thermography data after running: Preliminary study. Infrared Physics \& Technology 109, 103382. DOI: https://doi.org/10.1016/j.infrared.2020.103382.

[8] Vedran Hadžić, Brane Širok, Aleš Malneršič and Milan Čoh, 2019. Can infrared thermography be used to monitor fatigue during exercise? A case study. Journal of Sport and Health Science 8, 1, 89-92. DOI: https://doi.org/10.1016/j.jshs.2015.08.002.

[9] Priscila dos Santos Bunn, Maria Elisa Koppke Miranda, Allan Inoue Rodrigues, Ravini de Souza Sodré, Eduardo Borba Neves and Elirez Bezerra da Silva, 2020. Infrared thermography and musculoskeletal injuries: A systematic review with meta-analysis. Infrared Physics \& Technology 109, 103435. DOI: doi.org/10.1016/j.infrared.2020.103435.

[10] Thomas W. Jones, Barry C. Shillabeer, and Marco Cardinale. 2020. Skin temperature, training load, and subjective muscle soreness in junior endurance athletes: A case study. International Journal of Sports Physiology and Performance 15, 9, 1349-1352. DOI: https://doi.org/10.1123/ijspp.2019-0748.

[11] Ivana Salopek Čubrić, Goran Čubrić and Vesna Marija Potočić Matković. Development of ergonomic sportswear based on thermal body mapping. In Proceedings of the 8th International Ergonomics Conference, December 2-5, 2020, Zagreb, Croatia. Springer International Publishing, ISBN: 978-3-030-66937-9.

[12] Deepti Gupta, Vijay Kumar Kothari and Yamini Jhanji. 2014. Heat and moisture transport in single jersey plated fabrics. Indian Journal of Fibre \& Textile Research 39, 2, 115-121.

[13] Renata Nemcokova, Viera Glombikova and Petra Komarkova. 2015. Study on liquid moisture transport of knitted fabrics by means of MMT, thermography and microtomography systems. AUTEX Research Journal 15, 4, 233-242. DOI: https://doi.org/10.1515/aut-2015-0022.

[14] Ivana Salopek Čubrić, Goran Čubrić and Vesna Marija Potočić Matković. Use of thermography to analyze the influence of Yarn properties on fabric drying. In Proceedings of 7th International Conference on Textile, November 10-11, 2016, Tirana, Albania.

[15] Lubos Hes and Mariana Ursache. 2011. Effect of composition of knitted fabrics on their cooling efficiency at simulated sweating. Indian Journal of Fibre \& Textile Research 36. 3, 281-284.

[16] Jefferson M. Souza, Sandra Sampaio, Welter C. Silva, Sidney G. de Lima, Andrea Zille and Raul Fangueiro. 2018. Characterization of functional single jersey knitted fabrics using non-conventional yarns for sportswear. Textile Research Journal 88, 3, 275-292. DOI: https://doi.org/10.1177/0040517516677226.

[17] C. Prahsarn, R. L. Barker and B. S. Gupta. 2005. Moisture vapor transport behavior of polyester knit fabrics. Textile Research Journal 75, 4, 346-351. DOI: https://doi.org/10.1177/0040517505053811.

[18] Flir. FLIR E6. Retrieved from https://www.flir.com/products/e6/. 
[19] ISO 18434-1: Condition monitoring and diagnostics of machines - Thermography - Part 1: General procedures.

[20] Zofia Drzazga, Mariusz Binek, llona Pokora and Ewa Sadowska-Krepa. 2018. A preliminary study on infrared thermal imaging of cross-country skiers and swimmers subjected to endurance exercise. Journal of Thermal Analysis and Calorimetry 134, 701-710. DOI: https://doi.org/10.1007/s10973-018-7311-y.

[21] Jose Ignacio Priego Quesada, Natividad Martínez, Rosario Salvador Palmer, Agnes Psikuta, Simon Annaheim, René Michel Rossi, José Miguel Corberán, Rosa M. Cibrián Ortiz de Anda and Pedro PérezSoriano. 2016. Effects of the cycling workload on core and local skin temperatures. Experimental Thermal and Fluid Science 77, 91-99. DOI: https://doi.org/10.1016/j.expthermflusci.2016.04.008.

[22] Giovanni Tanda. 2015. The use of infrared thermography to detect the skin temperature response to physical activity. Journal of Physics: Conference Series 655, 1, 1-10. DOI: https://doi.org/10.1088/17426596/655/1/012062. 